\title{
A multi-analytical approach for the identification of the natural resin from the Ming tomb in Shaanxi, China
}

\author{
Lang Guo ${ }^{1,2}$, Yaxu Zhang ${ }^{3}$, Liqin Wang ${ }^{1,2^{*}}$, Xing Zhao ${ }^{1,2}$, Fuwei Yang ${ }^{1,2}$, Meiman Peng ${ }^{1}$, Jinyi Guo ${ }^{1}$, Kun Li ${ }^{3}$ and \\ Xiaomeng Wang ${ }^{3}$
}

\begin{abstract}
Several well-preserved polychrome lacquered coffins were found in Zhang Dong family's tombs in Shaanxi, China, rare in the history of archaeological excavation. In the lacquered coffins, a large amount of dark solid of suspected natural resin was unearthed with mysterious compositions and uses, exerting a tremendous fascination on archaeologists. In this work, a new method was explored for the identification of the suspected natural resin, mainly based on thermogravimetry (TG), elemental analysis (EA), scanning electron microscopy-energy dispersive spectrometry (SEM-EDS), matrix-assisted laser desorption ionisation time-of-flight mass spectrometry (MALDI-TOF-MS) and Fourier transform infrared spectrometry (FT-IR). The results suggested that the sample was mainly composed of organics with a content of $81.66 \%$ and little inorganics with a content of $2.21 \%$ by water excluded. Rosin with the main component of abietic acid (molecular formula $\mathrm{C}_{20} \mathrm{H}_{30} \mathrm{O}_{2}$ ) was identified as the principal component of the sample. Dehydrogenated abietic acid (DHA) and other oxides were also tested out. FT-IR confirmed the identification results. SEM revealed the rough surfaces evenly covered with holes of similar sizes. The use of this method directly obtained integral quasimolecular ion fragments and molecular components of the sample. As a result, intricate multi-stage mass spectrometry is avoidable, which dramatically simplifies the analysis procedure. This approach is simple and effective for the identification of precious relic samples, requires no references, and has potential for the analysis of these kinds of unknown samples. Especially, for the first time, EA is used to identify natural resins from archaeological sites.
\end{abstract}

Keywords: Natural resin, TG, EA, SEM-EDS, MALDI-TOF-MS, FT-IR, Component identification, Cultural relics

\section{Introduction}

In September 2011, Shaanxi Academy of Archaeology conducted an archaeological excavation at Jinghe Industrial Park in Gaoling County, Xi'an City, with 26 tombs excavated [1]. Among them, the graves of Zhang Dong (1535-1585 A.D., an official in charge of seals in the Ming Dynasty) family are of paramount importance. They are regarded as the best-preserved Ming Dynasty family tombs discovered so far in Shaanxi Province. Polychrome lacquered coffins painted with peony, lotus,

\footnotetext{
*Correspondence: wangliqinnwuedu@163.com

1 School of Cultural Heritage, Northwest University, Xi'an 710127, China

Full list of author information is available at the end of the article
}

phoenix, peacock and some other exquisite patterns were discovered, well-preserved, which is rare in the history of archaeological excavation. In the lacquered coffins, a large amount of unknown solid of suspected natural resin was unearthed, with a dark grey surface, yellow opaque cross-sections, and a thickness of about $1.0 \mathrm{~cm}$. We analysed the lacquered coffin's craftsmanship and materials in 2015 [2], but the unknown solid has never been identified. For research, preservation and restoration, it is indispensable to investigate the compositions and functions of the suspected natural resin.

After a long period of burial in the geological environment, the natural resin may be oxidised and degraded, which may bring challenges to its identification at a

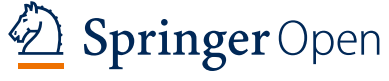

(c) The Author(s) 2021. Open Access This article is licensed under a Creative Commons Attribution 4.0 International License, which permits use, sharing, adaptation, distribution and reproduction in any medium or format, as long as you give appropriate credit to the original author(s) and the source, provide a link to the Creative Commons licence, and indicate if changes were made. The images or other third party material in this article are included in the article's Creative Commons licence, unless indicated otherwise in a credit line to the material. If material is not included in the article's Creative Commons licence and your intended use is not permitted by statutory regulation or exceeds the permitted use, you will need to obtain permission directly from the copyright holder. To view a copy of this licence, visit http://creativecommons.org/licenses/by/4.0/. The Creative Commons Public Domain Dedication waiver (http://creativeco mmons.org/publicdomain/zero/1.0/) applies to the data made available in this article, unless otherwise stated in a credit line to the data. 
molecular level. A commonly used method for identifying natural resins is gas chromatography-mass spectrometry (GC-MS) [3-6], by which the mixed components are separated and then qualitatively analysed [7]. However, complex pre-treatments limit its wide application. Nuclear magnetic resonance (NMR) facilitates inferring the precise molecular structures $[8,9]$, but for archaeological samples with complex and mixed compositions, the data may be challenging to interpret. As complementary methods, Raman spectroscopy and Fourier transform infrared spectroscopy (FT-IR) provide information on the vibrational spectra of natural resins [10-12], but databases or standard samples are usually required as references. Consequently, for the identification of the suspected natural resin with an unknown chemical background in this case, the methods mentioned, with intricate analysis procedures and requirements of references, may not be appropriate.

In this work, an approach based on TG, EA, SEMEDS and MALDI-TOF-MS was explored to examine the compositions of the suspected natural resin in the lacquered coffin unearthed from the Ming tomb. FT-IR was also adopted as a verification method. This approach is efficient and requires no references, which furnishes convenience to identify unknown resins found in archaeological sites. In particular, EA is used to identify natural resins in cultural objects for the first time.

\section{Experimental}

Samples

Samples were collected from the left side of the lacquered coffin of tomb M9-1, 0.6 m from the skull and $0.3 \mathrm{~m}$ deep in the coffin (Fig. 1a). The outer layer is black or dark grey, dried up, while the inner layer is yellow and opaque. Take a slice from the inner layer and name it Samp (Fig. 1b).

\section{Reagents}

Rosin (AR, Fig. 1c) was purchased from Macklin Biochemical Co., Ltd., (Shanghai, China). Generally, rosin is a light yellow and semi-transparent product of pine resin after distillation of volatile oil. It is mainly composed of resin acid, fatty acid, and neutral substances. Resin acid, a diterpene compound with a molecular formula of $\mathrm{C}_{19} \mathrm{H}_{29} \mathrm{COOH}$, is the principal component, accounting for more than $90 \%$ of rosin. There are four isomers in resin acid: abietic acid, neoabietic acid, levopimaric acid and palustric acid, whose chemical structures are shown in Fig. 2 [13]. After distillation, abietic acid is the main isomer.

\section{Apparatus and conditions \\ Thermogravimetric analysis (TG)}

The quantitative analysis of inorganic and organic components in Samp was carried out by a TG/DSC 3 + thermal analyser (Mettler Toledo, Switzerland). The thermal performance of rosin reagent was also studied

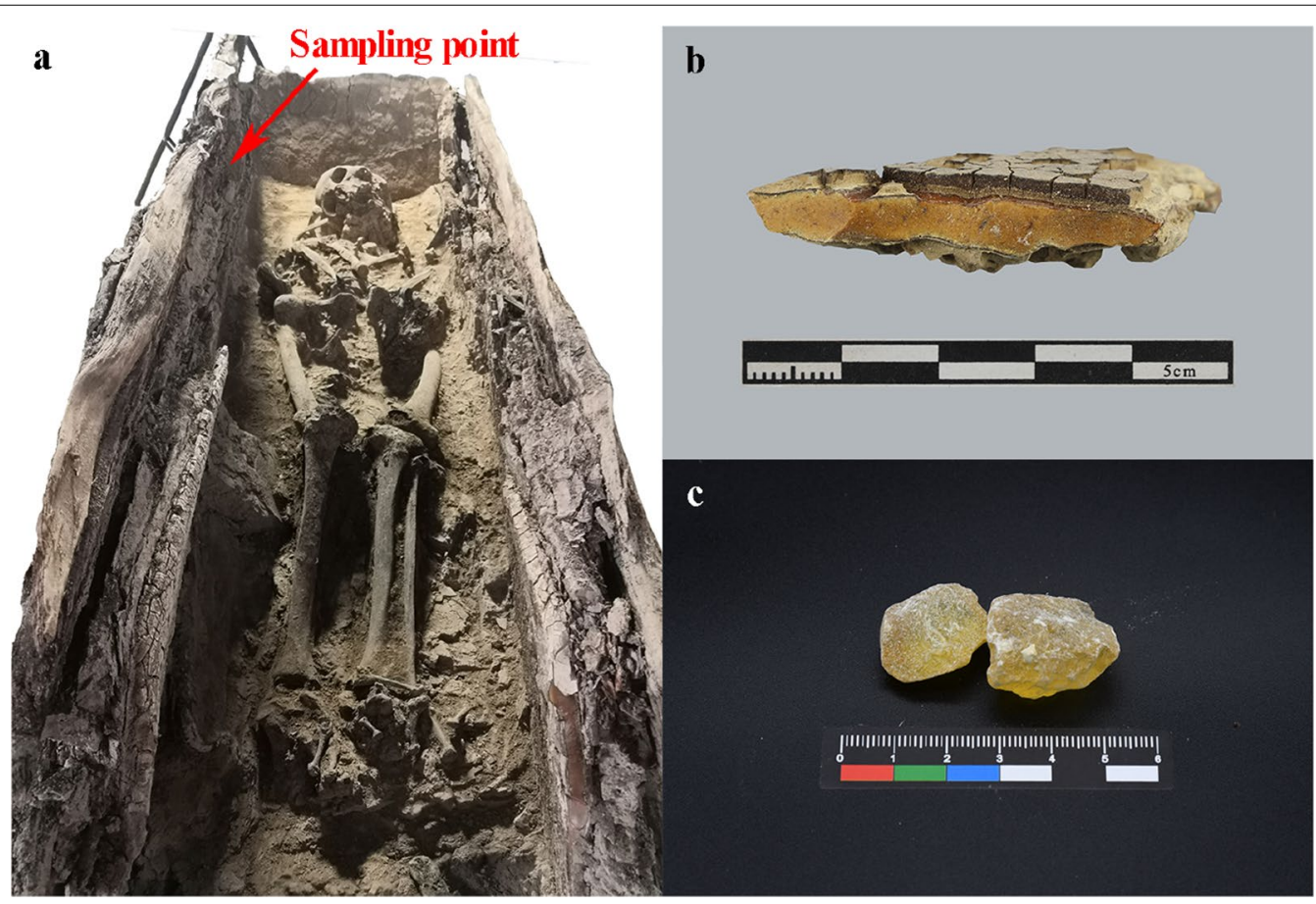

Fig. 1 a Polychrome lacquered coffin of M9-1. b Samp. c Rosin reagent 


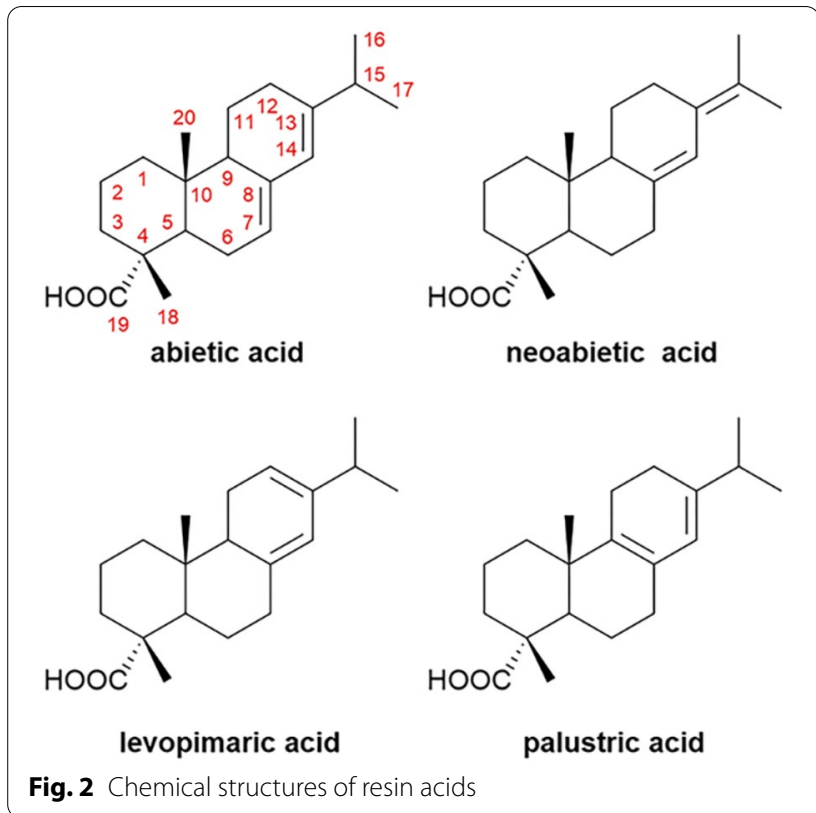

for comparison. Take 2-5 mg sample and spread it flat on the bottom of an alumina crucible. The temperature was programmed to increase from 50 to $1000{ }^{\circ} \mathrm{C}$ with a speed of $15{ }^{\circ} \mathrm{C} / \mathrm{min}$ in a nitrogen atmosphere. Origin Pro 2021b was used for data processing.

\section{Elemental analysis (EA)}

The content of carbon, hydrogen and nitrogen was obtained by a vario EL cube CHNS elemental analyser (Elementar, Germany). Before measurement, the sample was vacuum dried at $30{ }^{\circ} \mathrm{C}$ for $24 \mathrm{~h}$ to eliminate the interference of moisture. The sampling mass was 1-3 mg. High-purity oxygen was used as the carrier gas. The temperatures of the oxidation and reduction tubes were 1150 and $850{ }^{\circ} \mathrm{C}$, respectively.

\section{Scanning electron microscope analysis-energy dispersive spectrometry (SEM-EDS)}

The micromorphology of the sample surfaces was observed by a VEGA 3XMU scanning electron microscope (Tescan, Czech Republic) with a working voltage of $15 \mathrm{kV}$, a sample chamber pressure of $90 \mathrm{~Pa}$ and a working distance of $3 \mathrm{~mm}$.

An INCA X-Act energy-dispersive X-ray micro-analyser (Oxford Instruments plc, UK) was used for the analyses of carbon, oxygen and other elements. The working voltage was $20 \mathrm{kV}$, and the beam intensity was 13. The sample was vacuum dried at $30{ }^{\circ} \mathrm{C}$ for $24 \mathrm{~h}$ before measurement.

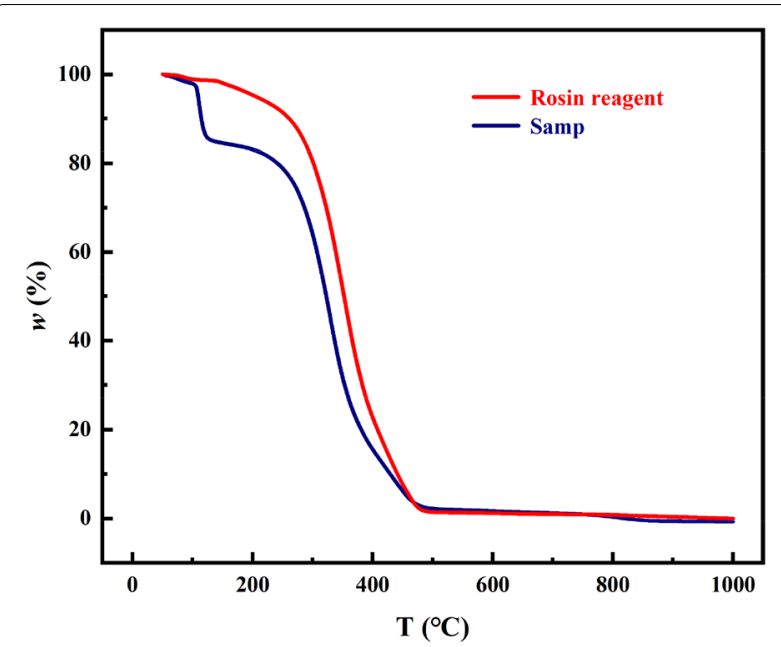

Fig. 3 TG results of rosin reagent and Samp

Matrix-assisted laser desorption ionisation time-of-flight mass spectrometry (MALDI-TOF-MS)

An AXIMA-CFR ${ }^{\mathrm{TM}}$ plus matrix-assisted laser desorption ionisation time-of-flight mass spectrometer (Kratos, UK) was applied to identify the compositions of the sample. Dissolve $0.4 \mathrm{mg}$ sample in $4 \mathrm{~mL}$ acetone for $15 \mathrm{~min}$ with ultrasonic assistance. Draw about $20 \mu \mathrm{L}$ supernatant and directly inject it for analysis. Negative electrospray ionisation was selected as the dissociation source. Scan from $\mathrm{m} / \mathrm{z} 50$ to 1500 .

\section{Fourier transform infrared spectrometry (FT-IR)}

A LUMOS TENSOR 27 Fourier transform infrared spectrometer (Bruker, Germany) was used to characterise the infrared spectra of the sample and rosin reagent. The range of $4000-600 \mathrm{~cm}^{-1}$ was measured with a resolution of $4 \mathrm{~cm}^{-1}$ and 24 times scans. Use OPUS 7.5 and Origin Pro 2021b for data processing. Select the asymmetric bending of methyl group at $1460 \mathrm{~cm}^{-1}$ as the standard for normalisation.

\section{Results and discussion}

\section{Thermal analysis}

For quantitative determination of the organics and inorganics in Samp, TG was carried out. The results (Fig. 3) showed that, within $50-175{ }^{\circ} \mathrm{C}$, Samp lost mass of $16.13 \%$ and the maximum rate of mass loss occurred at $110{ }^{\circ} \mathrm{C}$, which were corresponding to the process of evaporating liquid water and volatile ingredients. According to the literature, the decomposition of organics occurs within $175-500{ }^{\circ} \mathrm{C}$ [14], in which Samp had a mass loss of $81.66 \%$. The maximum rate of mass loss occurred at $330{ }^{\circ} \mathrm{C}$, which is consistent with the decomposition of 
abietic acid reported in the literature [15]. Consequently, this process is the thermal decomposition of organics in Samp, which possibly is rosin. Up to $500{ }^{\circ} \mathrm{C}$, Samp had a mass loss of $97.79 \%$, while $2.21 \%$ of mass remained, which referred to inorganics. Thus, Samp comprises water and volatile ingredients of $16.13 \%$, organics (possibly is rosin) of $81.66 \%$ and inorganic impurities of $2.21 \%$.

The thermal properties of rosin reagent (Fig. 3) were also studied. The rosin reagent is analytically pure. Therefore, unlike Samp, there is no mass loss that indicates the presence of water and volatile ingredients at around $110{ }^{\circ} \mathrm{C}$. Within $175-470{ }^{\circ} \mathrm{C}$, the thermal decomposition of rosin reagent was similar to that of Samp. From about $470{ }^{\circ} \mathrm{C}$ on, the two curves overlapped. These results may imply the similarities of the two components.

\section{Element analysis}

$\mathrm{X}$-ray fluorescence spectrometry (XRF) is the most widely used element analysis method for cultural heritage. XRF is effective for analysing the elements from sodium to uranium, but fails to achieve sufficient accuracy for the determination of carbon. As a result, it is mainly used for the detection of inorganic elements. The results of the thermogravimetry provided an indication of organics as the main components of the analyte. However, the determination of organic elements is scarce in the field of cultural heritage. In our previous research, elemental analysis was used for the quantitative determination of protein in the coloured paintings in the Summer Palace for the first time [16]. The sample amount was only 2-3 mg, but high accuracy with a recovery of $100.15 \%$ was attained [17], which has significant advantages for the analysis of precious organic relic samples. Likewise, in this work, elemental analysis was applied for the accurate admeasurement of organic elements.

The results showed that the content of carbon and hydrogen in Samp was $64.93 \%$ and $8.52 \%$, respectively, while nitrogen was not detected. When EA being performed, dynamic combustion is adopted to make the sample decompose and then further react at a high temperature in a pure oxygen environment. Finally, carbon, hydrogen and nitrogen are converted to $\mathrm{CO}_{2}, \mathrm{H}_{2} \mathrm{O}$ and $\mathrm{N}_{2}$, respectively. The content of each element in the sample can be obtained by thermal conductivity detection after separation by chromatography. Oxygen is not examined in EA.

EDS was used to detect oxygen for supplementary analysis. The results showed that the content of carbon and oxygen was $86.76 \%$ and $13.24 \%$, respectively. Since EDS was only able to detect the elements from boron to uranium, hydrogen was absent from the detection. The data obtained was the result after normalisation, showing the relative content of elements.
From EA and EDS results, the atomic number ratio of carbon, hydrogen and oxygen in Samp $\left(\mathrm{CH}_{1.5634} \mathrm{O}_{0.1145}\right)$ was deduced, which was close to that of abietic acid $\left(\mathrm{CH}_{1.5} \mathrm{O}_{0.1}\right)$. Abietic acid, with a chemical formula of $\mathrm{C}_{20} \mathrm{H}_{30} \mathrm{O}_{2}$ and a molar mass of 302.46, is the main component of rosin. Based on carbon, the relative errors of hydrogen and oxygen of Samp are $4.23 \%$ and $14.50 \%$, respectively.

Water and inorganic impurities contained in Samp could interfere with the element analysis results. Therefore, the samples were vacuum dried to remove water. Samp contained few inorganic impurities with a content of $2.21 \%$, and even no inorganic element was detected by EDS. Only carbon and hydrogen were detected in EA, while other elements (the main constituent elements of inorganic impurities) were not detected. Therefore, the interference of inorganic impurities was weak.

\section{Composition analysis}

The compositions of Samp were identified by MALDITOF-MS. Rosin reagent was used for comparative validation. Using electrospray ionisation avoids the fragmentation and decomposition of samples, making it easy to obtain the integral quasi-molecular ions which indicate the molar mass. In the mass spectrum of Samp (Fig. 4b), the base peak [m/z 301.2173, $\left.(\mathrm{M}-\mathrm{H})^{-}\right]$assigns to the molecular ion peak, providing an implication of the molar mass of Samp. On the basis of the results of element analysis and MALDI-TOF-MS, it is inferred that

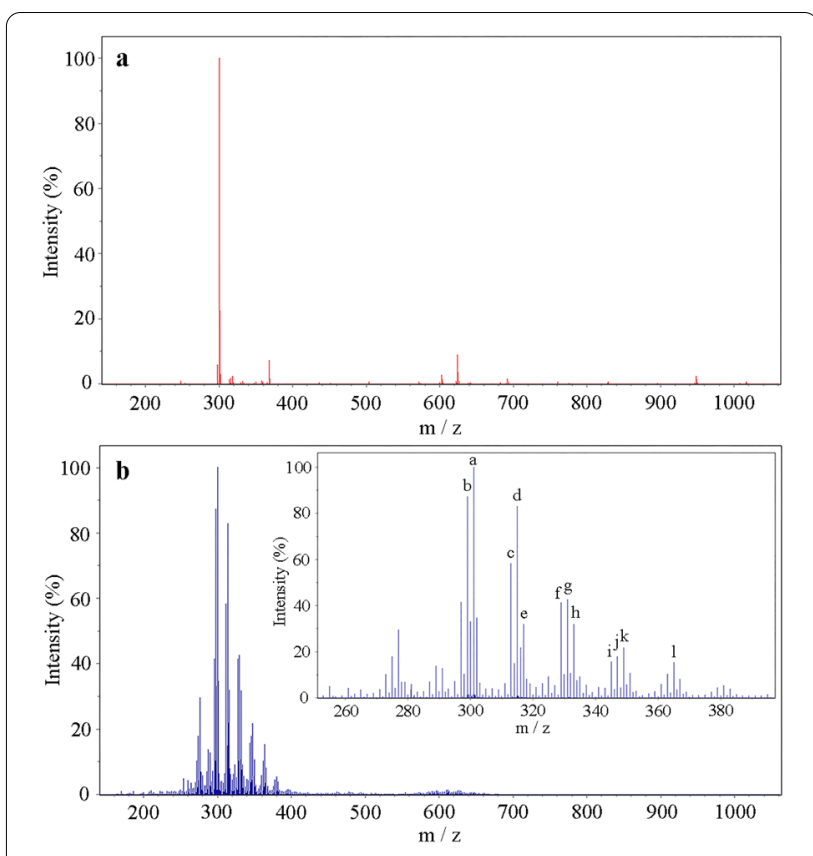

Fig. 4 MALDI-TOF-MS spectra: a Rosin reagent. b Samp 
the molecular formula of the main component of Samp is $\mathrm{C}_{20} \mathrm{H}_{30} \mathrm{O}_{2}$, which is abietic acid, the principal component of rosin. Therefore, Samp was identified as rosin. Rosin reagent has almost the same base peak $[\mathrm{m} / \mathrm{z}$ 301.2162, $(\mathrm{M}-\mathrm{H})^{-}$, in Fig. 4a] as Samp, confirming the inference above.

Besides, the appearance and physical properties of Samp are similar to those of rosin reagent: colour of amber, soluble in acetone, and insoluble in water. The combined use of EA, EDS and MALDI-TOF-MS directly obtained the resin's molecular information to be tested, getting the leading component identified efficiently. As a consequence, complex multi-stage mass spectrometry is avoidable, which dramatically simplifies the analysis procedure.

In addition to abietic acid, various oxidation products (Table 1; Fig. 4b) were tested out in Samp. Based on our results of MALDI-TOF-MS and the literature [13], the possible isomerisation and oxidation pathways of resin acids are inferred as shown in Scheme 1. Pine resin was collected, then heated and purified. By these processes, volatile oil was removed; meanwhile, the isomerisation of resin acids occurred. The latter can be explained by the transfer of protons. The isomerisation tends to form abietic acid, and finally, an equilibrium state of the isomers is obtained. Abietic acid is easily oxidised due to the existence of an active conjugated double bond. Dehydroabietic acid (DHA) could be formed by dehydrogenation between $\mathrm{C}-11$ and $\mathrm{C}-12$. The introduction of oxygen leads to further oxida-

Table 1 MALDI-TOF-MS results of Samp

\begin{tabular}{llll}
\hline Peak & Possible compound & $\begin{array}{l}\text { Molecular } \\
\text { formula, } \\
{[\mathbf{M}-\mathrm{H}]^{-}}\end{array}$ & $\begin{array}{l}\text { Mono-isotopic } \\
\text { mass, [M-H }]^{-}\end{array}$ \\
\hline $\mathrm{b}$ & DHA & $\mathrm{C}_{20} \mathrm{H}_{27} \mathrm{O}_{2}$ & 299.2018 \\
$\mathrm{a}$ & Abietic acid & $\mathrm{C}_{20} \mathrm{H}_{29} \mathrm{O}_{2}$ & 301.2173 \\
c & oxo-DHA & $\mathrm{C}_{20} \mathrm{H}_{25} \mathrm{O}_{3}$ & 313.1786 \\
d & OH-DHA/oxo-abietic acid & $\mathrm{C}_{20} \mathrm{H}_{27} \mathrm{O}_{3}$ & 315.1946 \\
e & OH-abietic acid & $\mathrm{C}_{20} \mathrm{H}_{29} \mathrm{O}_{3}$ & 317.2039 \\
f & OH-oxo-DHA & $\mathrm{C}_{20} \mathrm{H}_{25} \mathrm{O}_{4}$ & 329.1741 \\
g & diOH-DHA & $\mathrm{C}_{20} \mathrm{H}_{27} \mathrm{O}_{4}$ & 331.1883 \\
h & Peroxy-abietic acid & $\mathrm{C}_{20} \mathrm{H}_{29} \mathrm{O}_{4}$ & 333.2007 \\
i & diOH-oxO-DHA & $\mathrm{C}_{20} \mathrm{H}_{25} \mathrm{O}_{5}$ & 345.1679 \\
j & triOH-DHA & $\mathrm{C}_{20} \mathrm{H}_{27} \mathrm{O}_{5}$ & 347.1805 \\
k & triOH-abietic acid & $\mathrm{C}_{20} \mathrm{H}_{29} \mathrm{O}_{5}$ & 349.1953 \\
I & tetraOH-abietic acid & $\mathrm{C}_{20} \mathrm{H}_{29} \mathrm{O}_{6}$ & 365.1908 \\
\hline
\end{tabular}

tion, which may be achieved by forming a peroxide group by the double bond [13], or hydroxyl and carbonyl groups on abietic acid and DHA. In this study, trihydroxy-abietic acid (triOH-abietic acid) and tetrahydroxy-abietic acid
(tetraOH-abietic acid) were detected by MALDI-TOF-MS, which were rarely tested out in other methods. However, the exact structures of triOH-abietic acid and tetraOHabietic acid are still uncertain, which may be a mixture of various oxidation products. The mass-to-charge ratios detected in our experiments correspond to the compounds inferred in the literature [13], which provides assertive evidence for the oxidation process mentioned above. The dehydrogenation and oxidation of abietic acid will cause an increase of oxygen, which is a crucial reason why oxygen content in Samp is $14.50 \%$ higher than that in abietic acid.

Besides, the clusters detected in the range of $\mathrm{m} / \mathrm{z} 550$ 700 may refer to rosin dimers (Fig. 4), which is confirmed by reference [18].

FT-IR was carried out to verify the above identification results. According to the results of MALDI-TOF-MS and element analysis, the purchased rosin reagent was chosen for comparison. Figure 5a showed the normalised infrared spectra of rosin reagent and Samp. The main absorption peaks and their proposed assignments were summarised in Table 2. The two spectra corresponded well with similar shapes, indicating that the main component of rosin reagent and Samp are the same, which is abietic acid. 1695 and $3438 \mathrm{~cm}^{-1}$ were attributed to $\mathrm{C}=\mathrm{O}$ and $\mathrm{O}-\mathrm{H}$ stretching vibration respectively, which together suggested the presence of $\mathrm{COOH}$ in rosin reagent and Samp. Strong peaks such as $3000-2800,1460$ and $1385 \mathrm{~cm}^{-1}$ assigned to $\mathrm{C}-\mathrm{H}$ vibrations, of which positions and intensity were basically the same in the two spectra. Although the unsaturated bond signals were weak, they were also detected in both rosin reagent and Samp spectra (1639 and $\left.3080 \mathrm{~cm}^{-1}\right)$. It was worth noting that the peak at $890 \mathrm{~cm}^{-1}$ attributable to out-of-plane bending vibration of $=\mathrm{CH}$ was mediumstrong in the spectrum of rosin reagent, but very weak in the spectrum of Samp, indicating that $\mathrm{C}=\mathrm{C}$ bonds were partially destroyed and a relatively mature resin formed [19-22]. The aromatic ring skeleton vibration at 1607, 1556, 1540, 1521, and $1497 \mathrm{~cm}^{-1}$ (Fig. 5b) was only detected in the Samp spectrum (but not in the rosin reagent spectrum), which was the evidence that Samp contains dehydroabietic acid and its derivatives. All in all, from the FT-IR results, the main component of Samp was abietic acid, and oxidation occurred, which were consistent with the results of MALDI-TOF-MS and element analysis.

\section{Morphology analysis}

The SEM images of rosin reagent and Samp were shown in Fig. 6. At the micro-level, their morphologies were different. Rosin reagent surface was highly flat and smooth, while the Samp surface was extremely rough. In the high magnification image, it was observed that the Samp surface was evenly covered with holes of similar sizes (Fig. 6d). The existence of a large number of holes 


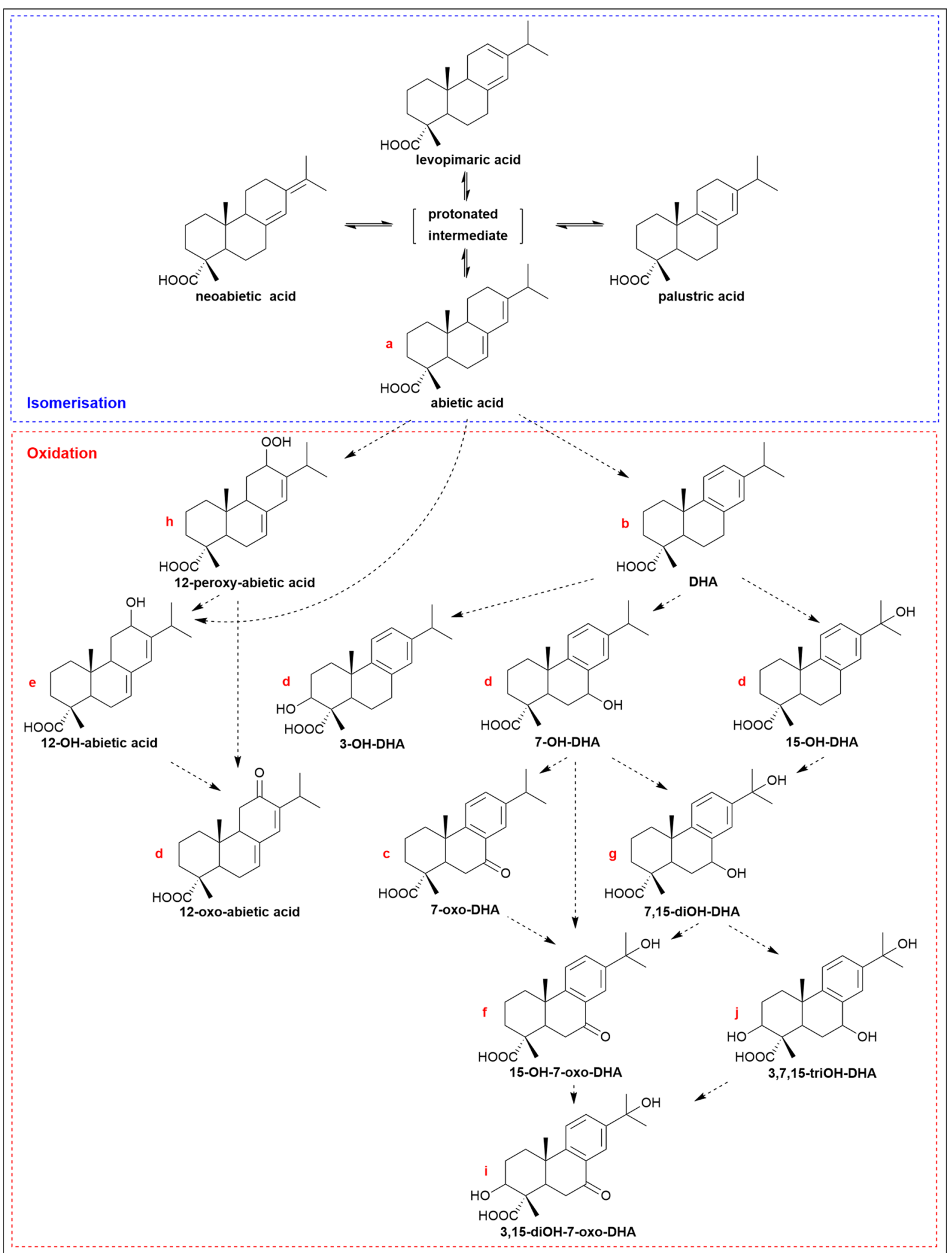

Scheme 1 Possible isomerisation (blue box) and oxidation (red box) pathways of resin acids. The vertical position of the compound reflects the degree of oxidation, except for compound $h$ 

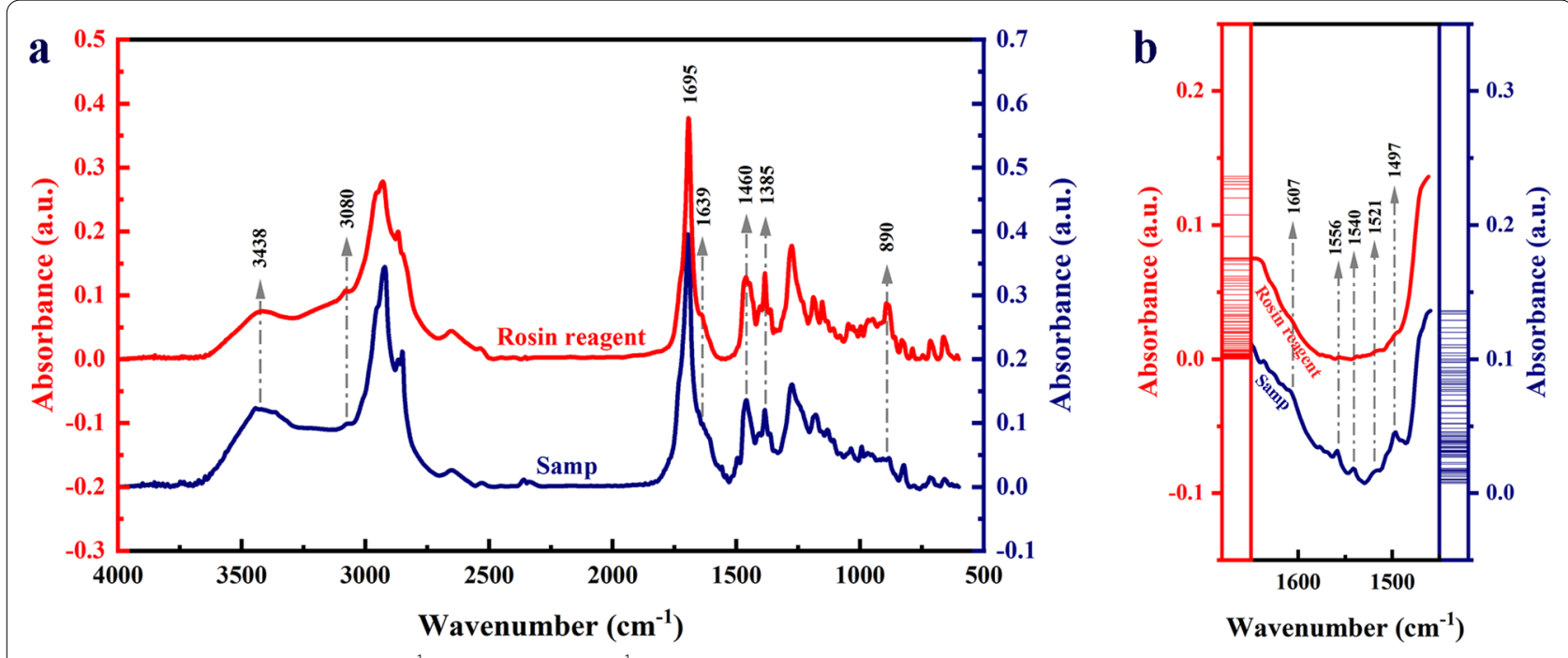

Fig. 5 FT-IR spectra: a $4000-600 \mathrm{~cm}^{-1}$. b $1650-1450 \mathrm{~cm}^{-1}$

Table 2 The main absorption peaks in FT-IR spectra of rosin reagent and Samp and their proposed assignments [19, 20]

\begin{tabular}{|c|c|c|}
\hline Rosin reagent $/ \mathrm{cm}^{-1}$ & Samp/cm $\mathrm{cm}^{-1}$ & Band assignment \\
\hline 3438 (b) & 3438 (b) & $V_{\mathrm{OH}}$ \\
\hline $3080(w)$ & $3076(w)$ & $v^{a s}=C-H$ \\
\hline 2958,2867 (vs) & 2955,2868 (vs) & $V^{a s}{ }_{\mathrm{CH} 3}, V_{\mathrm{CH} 3}^{s}$ \\
\hline 2929, 2851 (vs) & 2929, 2850 (vs) & $v^{a s} \mathrm{CH}_{2}, v_{\mathrm{CH} 2}^{s}$ \\
\hline 1695 (vs) & 1695 (vs) & $V_{C=O}$ \\
\hline $1639(w)$ & $1633(w)$ & $v_{C=C}$ \\
\hline (nb) & $1607,1556,1540,1521,1497(w)$ & $\gamma_{\psi}$ (vibration of aromatic ring skeleton) \\
\hline $1465(\mathrm{~m})$ & $1465(\mathrm{~m})$ & $\rho_{\mathrm{CH} 2}$ \\
\hline $1460(\mathrm{~m})$ & $1460(\mathrm{~m})$ & $\delta^{a s} \mathrm{CH}_{3}$ \\
\hline $1385,1365(m-w)$ & $1385,1365(m-w)$ & $\delta^{5} \mathrm{CH} 3$ \\
\hline $1278,1252,1233(\mathrm{~m}-\mathrm{w})$ & $1276,1252,1233(\mathrm{~m}-\mathrm{w})$ & $V_{\mathrm{C}-\mathrm{OH}}$ in carboxylic acids \\
\hline $1188,1179,1152(\mathrm{~m})$ & $1189,1179,1152(\mathrm{~m})$ & $v_{\mathrm{C}-\mathrm{OH}}$ in carboxylic acids and $2^{\circ}$ alcohols \\
\hline $1047,1038(w)$ & $1047,1038(w)$ & $v_{\mathrm{C}-\mathrm{OH}}$ in $1^{\circ}$ and $3^{\circ}$ alcohols \\
\hline $950(\mathrm{~m})$ & $950(\mathrm{~m})$ & $\mathrm{Y}_{\mathrm{O}-\mathrm{H}}$ in carboxylic acids \\
\hline $890(\mathrm{~m})$ & $886(v w)$ & $Y=C-H$ in $R^{\prime} C=C H R^{\prime \prime}$ \\
\hline
\end{tabular}

reduced the strength of the coating. Simultaneously, holes increased the specific surface area of Samp, which made it easier to deteriorate. At the macro-level, Samp showed a deep colour in appearance and low solubility, while, with light colour in appearance, rosin reagent dissolved in acetone completely, forming colourless and transparent solution (Fig. 7). All the physical distinctions mentioned between rosin reagent and Samp were due to the formation of dark oxidation products in Samp, as confirmed by chemical changes.

\section{Functions}

Rosin comes from pine trees. With strong vitality, pine tree is widely distributed in the northern hemisphere. It is one of the most widely distributed tree species in the world. China, with all the existing genera of Pinaceae and three endemic genera, has the richest distribution of Pinaceae. There are about 95 species of Pinaceae in China, accounting for $40 \%$ of the world's total species [23]. The wide distribution of Pinaceae provided objective conditions for the ancient Chinese to collect, process and use rosin.

As one of the most widely used natural resins, rosin was often used as adhesives [24, 25], varnish coatings 

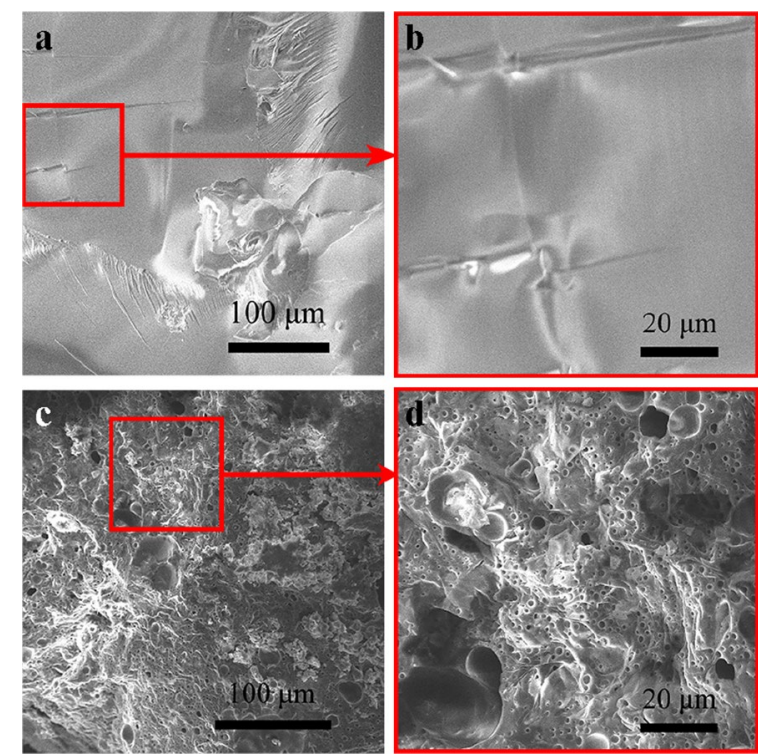

Fig. 6 SEM images: a Rosin reagent (500 x magnification). b Rosin reagent (2000 $\times$ magnification). c Samp $(500 \times$ magnification $) . \mathbf{d}$ Samp (2000 $\times$ magnification)

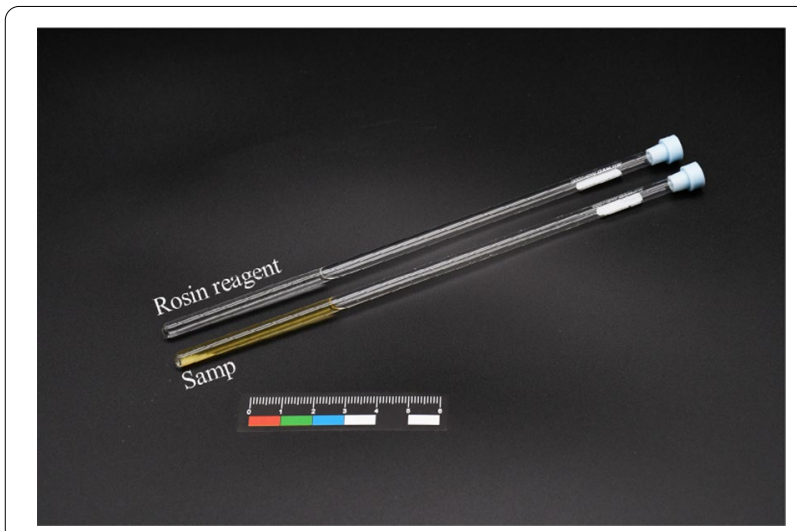

Fig. 7 Acetone solution of rosin reagent and Samp

[26, 27], medicines [28, 29] and other daily necessities, playing an essential role in ancient times. According to historical records [30], artificial collection of pine resin can be traced back to the Han Dynasty in China. With the invention of direct fire heating method, Chinese people mastered the technology of extracting rosin from pine resin. In the Tang Dynasty, rosin was widely used in gunpowder, movable type printing, shipbuilding, papermaking and other processes. During the Song Dynasty, Chinese rosin production flourished and exported to Arabia, Persia, India, and Southeast Asian countries. Although rosin production declined gradually after Yuan and Ming Dynasties, it was still used in daily necessities.
Thus, China has a tradition of processing and utilizing rosin.

In this case, rosin found in the Ming Dynasty tomb was used to coat the inner wall of the lacquered coffin. We hold the view that the functions are to seal the wooden coffin and preserve the corpse. Similar examples had been found in archaeological excavations [31]. During the Song, Yuan and Ming Dynasties, it gradually became popular to fill the gaps between the inner and outer coffins with a large amount of rosin. In the Song Dynasty, the ancient Chinese had recognised that rosin had the pleasing effect as a moisture-proof sealing material. Yuan Dynasty traveller Marco Polo also described in his travel notes the scene that Dunhuang people sprinkled scented gums and other drugs in coffins during burial ceremonies [32]. The gums mentioned include borneol, frankincense, myrrh, benzoin, styrax, ferulae resina, rosin and other resins. According to the 34th volume, the Wood, in Compendium of Materia Medica written by Li Shizhen, all these scented gums possessed the ability of sterilization [33]. The antimicrobial activity of rosin and its derivatives has been proved by experiments now [34-36]. Ancient Chinese believed that "death is a rebirth", advocated grand burials, and longed for immortality and eternity. As a readily available raw material with suitable viscosity, rosin has developed into a sealing material for coffins. Furthermore, together with the use of fabrics (wrapping corpses), fragrances, gold, jade, multi-layer coffins, deep burial and other materials or methods, rosin has formed a sophisticated burial system that played a positive role in the preservation of corpses.

\section{Preservation conditions}

In cultural relics resin samples, abietic acid oxides were often detected as principal components instead of abietic acid [37, 38]. However, in this case, abietic acid was tested out as the main component, while its oxides were in the minority, indicating that the resin was relatively well-preserved [39]. This was due to the thick rosin coating (about $1 \mathrm{~cm}$ ), by which the inner resin (where we took samples for test, Fig. 1b) was protected from the oxidation environment. As a result, a large amount of non-oxidised abietic acid was retained.

The use of rosin coating promoted the adhesive force at the joint and the hermetic seal of the coffin, which prevented the entry of external soil and air to a certain extent. Together with the deep burial, the rosin coating was conducive to the formation of a relatively anaerobic atmosphere inside the coffin, thereby preserving the organic matter [39]. It is worth mentioning that, after nearly 400 years of burial, the perishable wooden coffin has still been well-preserved. Until today, the lacquered coffin still maintains its original shape and painted 
patterns, like peony, lotus, etc., which is owing to the dual protection of the rosin coating inside of the coffin and the polychrome lacquer layer outside of the coffin.

\section{Conclusions}

In this work, a new approach was explored to identify the molecular compositions of natural resins unearthed in archaeological sites, mainly based on TG, EA, SEMEDS and MALDI-TOF-MS. FT-IR was also adopted as a verification method. This method is simple and does not require standard samples and databases as references, which has significant advantages for the identification of relic samples with unknown chemical backgrounds. It should be noted that EA is the first time applied to identify natural resins in cultural objects.

The analysis of the natural resin unearthed from the Ming tomb in Shaanxi verifies the feasibility of this method. The suspected resin was identified as rosin. It is inferred that the resin was used to seal the coffin and preserve the corpse. The efficient identification of MALDITOF-MS indicated that abietic acid dominated as the main component in Samp with a small amount of oxidation products such as DHA and OH-DHA, as confirmed by FT-IR. The morphology illustrated that the surface is rough and evenly covered with holes. Non-oxidised abietic acid as the main component means that the resin is relatively well-preserved, which is rare after a long period of burial. This is due to the thick rosin coating, by which the inner resin was protected from the oxidation environment. Under the dual protection of the rosin coating and the polychrome lacquer layer, the lacquered coffin was also well-preserved. This article provides valuable information for the research and preservation of this batch of samples, and establishes a new method for analysing natural resins.

\begin{abstract}
Abbreviations
TG: Thermogravimetry; EA: Elemental analysis; SEM-EDS: Scanning electron microscopy-energy dispersive spectrometry; MALDI-TOF-MS: Matrix-assisted laser desorption ionisation time-of-flight mass spectrometry; FT-IR: Fourier transform infrared spectrometry; DHA: Dehydrogenated abietic acid; GC-MS: Gas chromatography-mass spectrometry; NMR: Nuclear magnetic resonance; AR: Analytical reagent; XRF: X-ray fluorescence spectrometry; oxo-: Carbonyl$\mathrm{OH}-$ : Hydroxy-; diOH-: Dihydroxy-; triOH-: Trihydroxy-; tetraOH-: Tetrahydroxy-; vs: Very strong; m: Medium; w: Weak; vw: Very weak; b: Broad; nb: No band; $v$ : Stretching; $\delta$ and $\rho$ : In-plane scissoring and rocking, respectively; $\gamma$ : Out-ofplane bending; ${ }^{\text {as }}$ : Asymmetric; $^{\text {s: }}$ Symmetric.
\end{abstract}

\section{Acknowledgements}

The authors would like to thank Xiaoqing Wang (Northwest University) for the assistances of MALDI-TOF-MS testing and Juan Fan (Shaanxi Normal University) for the support of EA examination. Special thanks to the editors and the anonymous reviewers for their careful work and insightful feedback on this manuscript.

\section{Authors' contributions}

LW, LG and YZ contributed to the conception of the study; MP and JG performed the experiments; XZ contributed significantly to analysis and manuscript preparation; LG and LW performed the data analysis and wrote the manuscript; FY assisted in the FT-IR experiments and made useful suggestions for the results; $\mathrm{KL}$ and XW provided the samples and helped perform the analysis with constructive discussions. All authors read and approved the final manuscript.

\section{Funding}

The authors are grateful for the financial support by the Key Research and Development Plan of Shaanxi Province (2019ZDLSF07-05), Education Department of Shaanxi Province (20JZ092) and School of Cultural Heritage, Northwest University (2020WYYCY-02).

\section{Availability of data and materials}

The datasets used and/or analyzed during the current study are available from the corresponding author on reasonable request.

\section{Declarations}

\section{Competing interests}

The authors declare that they have no competing interests.

\section{Author details}

${ }^{1}$ School of Cultural Heritage, Northwest University, Xi'an 710127, China. ${ }^{2}$ Key Laboratory of Cultural Heritage Research and Protection Technology, Ministry of Education, Northwest University, Xi'an 710127, China. ${ }^{3}$ Shaanxi Academy of Archaeology, Xi'an 710054, China.

Received: 4 May 2021 Accepted: 31 Auqust 2021

Published online: 11 September 2021

\section{References}

1. Liu DY, Xing FL, Tian YQ, Yu CL, Wang XM, Zhao ZR, Miao YF, Li K, Xi L, Xiao JY. Review of archaeological discoveries dating from the Three-Kingdom to the Song-Yuan-Ming-Qing periods in Shaanxi (2008-2017). Archaeol Cult Relics. 2018. https://doi.org/10.3969/j.issn.1000-7830.2018.05.005.

2. Zhang T. Study on making processes and materials of painted lacquer coffins in Gaoling during Ming Dynasty. Dissertation. Xi'an: Northwest University; 2015.

3. Mezzatesta E, Perraud A, Vieillescazes C, Mathe C. GC-MS and PCA analyses of diterpenoids degradation state in 21 human mummies of Ancient Egypt dating from New Kingdom to Graeco-Roman Period. J Cult Herit. 2021;47:43-9.

4. Saravanakumar K, Park S, Sathiyaseelan A, Kim KN, Cho SH, Mariadoss AVA, Wang MH. Metabolite profiling of methanolic extract of Gardenia jaminoides by LC-MS/MS and GC-MS and its anti-diabetic, and anti-oxidant activities. Pharmaceuticals. 2021;14:102.

5. Mills JS, White R. Natural resins of art and archaeology their sources, chemistry, and identification. Stud Conserv. 1977;22:12-31.

6. Colombini MP, Andreotti A, Bonaduce I, Modugno F, Ribechini E. Analytical strategies for characterizing organic paint media using gas chromatography/mass spectrometry. Acc Chem Res. 2010;43:715-27.

7. Wu C, Wang LQ, Yang L, Ma ZZ. Application of gas chromatography-mass spectrometry for the identification of organic compounds in cultural relics. Chin J Anal Chem. 2013:41:1773-9.

8. Salome-Abarca LF, van der Pas J, Kim HK, van Uffelen GA, Klinkhamer PGL, Choi YH. Metabolic discrimination of pine resins using multiple analytical platforms. Phytochemistry. 2018;155:37-44.

9. Spinella A, Malagodi M, Saladino ML, Weththimuni ML, Caponetti E, Licchelli M. A step forward in disclosing the secret of Stradivari's varnish by NMR spectroscopy. J Polym Sci Part A Polym Chem. 2017;55:3949-54.

10. Daher C, Paris C, Le Ho AS, Bellot-Gurlet L, Echard JP. A joint use of Raman and infrared spectroscopies for the identification of natural organic media used in ancient varnishes. J Raman Spectrosc. 2010;41:1494-9.

11. Invernizzi C, Fichera GV, Licchelli M, Malagodi M. A non-invasive stratigraphic study by reflection FT-IR spectroscopy and UV-induced 
fluorescence technique: the case of historical violins. Microchem $\mathrm{J}$. 2018;138:273-81.

12. Azémard C, Vieillescazes $C$, Ménager M. Effect of photodegradation on the identification of natural varnishes by FT-IR spectroscopy. Microchem J. 2014;112:137-49.

13. van den Berg KJ, Boon JJ, Pastorova I, Spetter LFM. Mass spectrometric methodology for the analysis of highly oxidized diterpenoid acids in Old Master paintings. J Mass Spectrom. 2000;35:512-33.

14. Manzano E, Bueno AG, Gonzalez-Casado A, del Olmo M. Mortars, pigments and binding media of wall paintings in the 'Carrera del Darro' in Granada. Spain J Cult Herit. 2000;1:19-28.

15. Nong WJ, Chen XP, Wang LL, Liang JZ, Zhong LP, Tong ZF. Thermal decomposition kinetics of abietic acid in static air. Chin J Chem Eng. 2013;21:724-9.

16. Wang $L Q$, Yang $L$, Zhou WH, Yan J, Guo R. Analysis of the techniques and materials of the coloured paintings in the Renshou Hall in the Summer Palace. Anal Methods. 2015;7:5334-7.

17. Wang LQ, Guo R, Zhou WH, Fan XL, Zhao LJ, Ma T. Determination of contents of protein and starch in plaster materials used in colored drawing on Chinese ancient building. J Lanzhou Univ. 2012;48:136-40.

18. Tirat S, Degano I, Echard JP, Lattuati-Derieux A, Lluveras-Tenorio A, Marie A, Serfaty S, Le Huerou JY. Historical linseed oil/colophony varnishes formulations: study of their molecular composition with micro-chemical chromatographic techniques. Microchem J. 2016;126:200-13.

19. Kaal J, Seijo MM, Oliveira C, Wagner-Wysiecka E, McCoy VE, Kraemer MMS, Kerner A, Wenig P, Mayo C, Mayo J. Golden artefacts, resin figurines, body adhesives and tomb sediments from the pre-Columbian burial site El Caño (Gran Coclé, Panamá): tracing organic contents using molecular archaeometry. J Archaeol Sci. 2020;113:105045.

20. Wagner-Wysiecka E. Mid-infrared spectroscopy for characterization of Baltic amber (succinite). Spectrochim Acta A. 2018;196:418-31.

21. Langenheim JH, Beck CW. Infrared spectra as a means of determining botanical sources of amber. Science. 1965;149(3679):52-4.

22. Daher C, Bellot-Gurlet L, Le Ho AS, Paris C, Regert M. Advanced discriminating criteria for natural organic substances of Cultural Heritage interest: spectral decomposition and multivariate analyses of FT-Raman and FT-IR signatures. Talanta. 2013;115:540-7.

23. Li N. Studies on the geographic distribution, origin and despersal of the family Pinaceae Lindl. J Syst Evol. 1995;33(2):105-30.

24. Helwig K, Monahan V, Poulin J, Andrews TD. Ancient projectile weapons from ice patches in northwestern Canada: identification of resin and compound resin-ochre hafting adhesives. J Archaeol Sci. 2014;41:655-65.

25. Wu M, Zhang BJ, Yang JC. Detection of millennial rosin in empress Xiao's crown by ELISA. Microchem J. 2020;154:104581.

26. Bertrand L, Robinet L, Cohen SX, Sandt C, Le Hô AS, Soulier B, LattuatiDerieux A, Echard JP. Identification of the finishing technique of an early eighteenth century musical instrument using FT-IR spectromicroscopy. Anal Bioanal Chem. 2011;399:3025-32.
27. Evershed RP, Jerman K, Eglinton G. Pine wood origin for pitch from the Mary Rose. Nature. 1985;314:528-30.

28. Izzo FC, Lodi GC, de Agredos Pascual MLV. New insights into the composition of historical remedies and pharmaceutical formulations: the identification of natural resins and balsams by gas chromatographic-mass spectrometric investigations. Archaeol Anthropol Sci. 2021;13:2.

29. Lodi GC, Borsato G, de Agredos Pascual MLV, Izzo FC. Disclosing the composition of unknown historical drug formulations: an emblematic case from the Spezieria of St. Maria della Scala in Rome. Anal Bioanal Chem. 2020;412:7581-93.

30. Xu ZY. Investigation and research into colophony excavated from the graves at Songyang in Zhejiang. Chin J Hist Sci Technol. 1998;19(2):68-72.

31. Bai GX. An introduction to the Yuan tomb discovered in Qipanshan, Anqing. Chin Cult Relics. 1957. https://www.cnki.com.cn/Article/CJFDT otal-WENW195705021.htm.

32. Huo W. Several issues concerning embalming in the tombs of Song, Yuan and Ming Dynasty. J Sichuan Univ. 1987. http://www.cnki.com.cn/Article/ CJFDTotal-SCDZ198704019.htm.

33. Li SZ. The compendium of materia medica (本草纲目), Ming Dynasty, vol. 34. Nanjing; 1593

34. Savluchinske-Feio S, Curto MJM, Gigante B, Roseiro JC. Antimicrobial activity of resin acid derivatives. Appl Microbiol Biotechnol. 2006;72:430-6.

35. Tao P, Wu CY, Hao J, Gao YQ, He XH, Li J, Shang SB, Song ZQ, Song J. Antifungal application of rosin derivatives from renewable pine resin in crop protection. J Agric Food Chem. 2020;68:4144-54.

36. Niu X, Liu YT, Song Y, Han JQ, Pan H. Rosin modified cellulose nanofiber as a reinforcing and co-antimicrobial agents in polylactic acid/chitosan composite film for food packaging. Carbohydr Polym. 2018;183:102-9.

37. Pozhidaev V, Kamaev A, Nuretdinova A, Kovalchuk M, Yatsishina E, Greshnikov E, Sivitskiy M, Devlet E. Identification of the residue in the Bolgar Medieval sphero-conical vessel by gas chromatography-mass spectrometry. Archaeometry. 2017;59(6):1095-104.

38. Jones J, Higham TFG, Chivall D, Bianucci R, Kay GL, Pallen MJ, Oldfield R, Ugliano F, Buckley SA. A prehistoric Egyptian mummy: evidence for an 'embalming recipe' and the evolution of early formative funerary treatments. J Archaeol Sci. 2018;100:191-200.

39. Qanbari-Taheri N, Karimy AH, Holakooei P, Kobarfard F. Organic residue analysis of Iron Age ceramics from the archaeological site of Kani-zirin, western Iran. Archaeometry. 2020;62(3):612-25.

\section{Publisher's Note}

Springer Nature remains neutral with regard to jurisdictional claims in published maps and institutional affiliations.

\section{Submit your manuscript to a SpringerOpen ${ }^{\circ}$ journal and benefit from:}

- Convenient online submission

- Rigorous peer review

- Open access: articles freely available online

- High visibility within the field

- Retaining the copyright to your article

Submit your next manuscript at $\boldsymbol{\nabla}$ springeropen.com 